\title{
SKY CASTLE: CONSUMING EDUCATION FROM THE CASES OF TWO TIGER PARENTS
}

\author{
Yuliyanto Chandra* \\ Program Magister Sastra, Fakultas Sastra dan Bahasa, Universitas Kristen Petra \\ Jl. Siwalankerto No. 121-131 Wonocolo, Surabaya, Jawa Timur 60236, Indonesia \\ yuliantoc1996@gmail.com
}

Received: $10^{\text {th }}$ July 2020/Revised: $27^{\text {th }}$ July 2020/Accepted: $24^{\text {th }}$ August 2020

How to Cite: Chandra, Y. (2020). Sky Castle: Consuming education from the cases of two tiger parents.

Lingua Cultura, 14(2), 151-159. https://doi.org/10.21512/lc.v14i2.6566

\begin{abstract}
The research aimed to analyze how the Korean series, SKY Castle, successfully captured the idea that education could be commoditized in consumer culture for ensuring class mobility, which was majorly done by two exemplary tiger parents in Korea. Methodologically, the research applied a qualitative approach and employed a detailed analysis of the main character and one supporting character, Han Suhjin and Cha Minhyuk, respectively. Both characters'actions and utterances would be selectively used to support the arguments of the research. Their relationship with other characters would also be used as further explanations. The research sheds light on how the two aforementioned characters fervently pursue and spend millions on education as it is perceived to strengthen their position in the social totem pole. The underlying theories to support the discussion are those of cultural and economic capital, consumption, commodification, and tiger parents. These are interconnected in the Korean context, especially due to the shifting value of education in the contemporary era.
\end{abstract}

Keywords: education consumption, consumer culture, cultural capital, tiger parent153, koing style, SKY Castle

\section{INTRODUCTION}

Education has been seen of magnitude for centuries. Its pivot is evident in how it is treated as a vehicle to reach success. The absence of it creates considerable difficulties to obtain a position in the professional realm proffering promising income. Whence great thinkers put it at the apex of the hierarchy of important components someone must undergo. Man who has founded Common School opines that social polyphony and political stability rely heavily on education. Similarly, Jefferson warns the uneducated to become parts of the educated citizenry. Religious artifacts such as those of Confucianism also heeds learning, interchangeable with virtues and education, as important.

Korea is one of the countries accenting the importance of education, especially because it is a country integrated with Confucian values. Historicity even encloses the influence of Confucianism in the massive favorable perception towards education (Levent \& Pehlivan, 2017). The arrival of Confucianism during the era of the Three Kingdoms of Korea has shaped the fabric of society. Serving as a national ideology, Confucianism is seen as of magnitude in retaining power and privilege and crucial to establishing state regulation. Its adherents perceive education as remarkably significant for social sustainability.

Moreover, the significance of education can also be traced back through socio-political circumstances dating back to the 1970s. During this epoch, Korea restored its economic downturn, the aftermath of the Korean division, in a rapid manner. This restoration went down in history as the 'Han River Miracle' (Howe, 2020). However, it must be noted that this miraculous transformation has a causal relationship with education (Levent \& Pehlivan, 2017).

Contemporarily, the 'education fever' is a terminology used to address Koreans' obsession over education (Kim \& Bang, 2017) that still lingers, not residually but strongly and statically across time. Oh (2010) and Woo and Hodges (2015) have argued that the obsession over education in contemporary society is partially credited to the belief that social success is obtainable through education. Oh (2010) has also attributed such a phenomenon to parents' psychological states who usually take charge of their children's 
education and enforce the idea that education is an indispensable asset to 'mingle' with the society and a vehicle to reach betterment. For such a reason, Korean mothers divide their focus between formal education and private education. The latter is predominantly used to ascertain academic success (Shin, Jahng, \& Kim, 2019). Therefore, education is analogous to the idea of investment, meaning that the parents who are obsessed over their children's education see the utilitarian facet of education. Investing in children's education is not only to vouchsafe 'bright future' for their children but also to benefit themselves from it.

Although education is important and its position in Korean society nowadays is not arguable, the debate can be directed to its exploitation. The word exploitation is indeed strong in the sense that it somehow carries negative weight to it. This exploitation of education is embodied in the way it is commoditized by people to fit into a certain imagined community; that is, to gain cosmopolitan membership. This embodiment further supports the notion of identity propounded by Burke (in Harsono, 2017), who says it is understood as 'what it means to be one is'. Inferred from Burke's phrase, the commodification of education to gain cosmopolitan membership is, therefore, an invitation for social acceptance and approval that is deemed to be pivotal. As Harsono (2017) has claimed for people who share this assertion, "to be in-between or average is a condition they would avoid at all cost."

Hence, for such an acceptance to ensue, cultural capital is at play. The extensive usage of cultural capital, the notion propounded by Pierre Bourdieu, has shed some light on understanding experiential aspects of an individual's life progress (Akua-Sakyiwah, 2016). Cultural capital manifests itself in three forms; embodied state, objectified state, and institutionalized state (Tan, Peng, \& Lyu, 2019). All states are treated as the primary tools to understand how education is converted into cultural capital to ensure the owner's participation in the targeted community and social mobility. These states constitute all the cultural goods that transmit prestige and status, both of which are translated into their capital to partake in social events.

Interestingly, cultural capital is converted into economic capital - defined as any assets convertible into money - due to its closeness to education consumption. Bourdieu explains that cultural capital can be converted into economic capital (as elaborated in Li \& Thorson, 2018). However, the transformation between the two capitals is complicated as cultural capital is manifested in three states. The embodied state transforms the external wealth into an integral part of a person (Li \& Thorson, 2018). Transforming this particular state into economic capital implies that a person's learning experience, including organizational involvement and internship - which is also related to time investment - is important in obtaining a job that proffers a higher salary. The objectified state is the materialization of the embodied state. Here, the visible test scores and transcript may serve as the determiner of the kind of job a person may obtain, resulting in the amount of money he/she earns. The last state is the institutionalized state, which can be in the form of academic credentials such as an academic degree. When converted into economic capital, the academic degree decides the degree of professionalism of a person. It hence determines how much money he/she can make out of the profession.

How education is remolded into economic capital to participate in a certain community must be framed in the concept of consumption. The value of education is dependent upon its consumption. Since consumption involves the actual use and enjoyment of goods and services (Rössel, 2011), it depends on how it is used and enjoyed. Its value can go beyond 'granting knowledge' to 'granting social status' for its consumers. As Lin (2019) has elucidated, the aspect of education consumption is not merely lucrative in the sense that it is for family investment in their own children, but it also socially mobilizes them in the social totem pole. Hence, the idea of consumption in relation to education is rudimentarily multidimensional. Consumer culture in Korea is seen in the extra effort that parents have to put forth in education. One example is private tutoring outside the class (Ha \& Park, 2017).

In the Korean context, however, the notion of education consumption is heavily interconnected with the idea of the tiger parenting style. The practice of excessive obsession over education is generally done by parents who adopt the parenting as mentioned earlier style. According to Chua (in Irawan, 2018), it is a rapacious style of parenting and generally rooted in the teaching of Confucianism. This parenting style is interchangeable with other parenting styles such as helicopter parenting style (Cui et al., 2019; Kwon, Yoo, \& Bingham, 2016; Kwon, Yoo, \& De Gagne, 2017), overparenting (Fletcher et al., 2020; Segrin et al., 2015), and parental overprotection (Kim, 2019). Parents adopting this parenting style prioritize academic excellence over others on the rationale that the pursuit of academic excellence may pave the way to success. Hence, failure in obtaining the expected result is intolerable in the eyes of this type of parent. Placing such a great value on grades at the expense of other necessary traits for a successful career and imposing excessive expectations on the children regarding their academic quest dismiss the psychological and emotional state of the children.

Tiger parenting style, which is synonymous with an authoritarian style based on Baumrind's taxonomy (Irawan, 2018), finds relevance in the Korean societal situation. Pressures from parents and demand to exert more efforts in their studies by taking additional after-school courses known as private tutoring, which negatively affects social life, have taken an emotional, social, and psychological toll (Kowen, Jang, \& Lee, 2019). In addition, studies also show how such overinvestment in education has resulted in more than just the children's suffering from the issues as mentioned earlier. It has also affected the family's income and resulted in disharmony among 
families and a high divorce rate (Hultberg, Calonge, \& Kim, 2017). Hence, Korea has recorded a high suicidal rate in Asia not only due to harshness from parents but also from the cutthroat competition to enroll in the university. It gives the rising standards in acceptance rate as the Korean government tries to compete with overseas educational institutions (Hultberg, Calonge, \& Kim, 2017).

Explication of the parents' adopted parenting style is not exclusively isolated in the Korean context. In fact, the condition where parents strive to provide the best possible education and benefit from their children's intensified schooling resonates with similar conditions in Japan and China, and other parts of the world. Parents' forced helmsmanship and participatory manner in the children's education reflects the so-called hierarchy that perpetually exists within East Asian family discourse that children must obey their parents. Parents must gain control over the children's life for they are partially indebted to them, and that parents have to be the absolute beings worth of obedience and respect. However, what lies beyond this parental attitude tends to be overlooked. This overlooked aspect relates to a great extent to societal constructs.

As a reflector of society, Sky Castle, a Korean TV drama, provides a source of understanding solidifying how education is involved in the process of commodification and consumption to disperse economic capital to the consumers who symbolically attempt to ascertain class mobility. Several studies have briefly mentioned Sky Castle regarding the documentation of Korea's prevalent parenting style (Yee, 2020) and parents' excessive desire for top-tier education (Kim et al., 2020; Kumar, 2020). However, none of the studies explores the consumption of education that is contextualized in Korea.

In the drama, such an excessive consumption of education is particularly embodied in Han Suhjin and Cha Minhyuk, two parents who dictate their children's education. Therefore, it behooves this research to posit the following questions; how are Han Suh-jin and Cha Min-hyuk exemplary of tiger parents who excessively consume education as a participatory means into a certain imagined community? The answer to this one question may provide insights into how consumption of education is first operated within the micro-level (family) and is further projected to reflect the macrolevel (societal practice).

\section{METHODS}

Methodologically, the research employs a detailed analysis of the main character and one supporting character, Han Suh-jin and Cha Min-hyuk, respectively. Both characters' actions and utterances will be selectively used to support the arguments of the research. Their relationship with other characters will also be used as further explanations. The discussion of the characters is informed by several relevant theories such as cultural and economic capital, commodification, consumption, and tiger parenting style.

\section{RESULTS AND DISCUSSIONS}

Towards the end of 2018 and nearly two months into 2019, the television industry in Korea was devoured by the immense popularity of Sky Castle, a serial television drama airing on JTBC. The drama won numerous awards in Korea and other countries and recorded the highest viewership rating among Cable TV dramas; $23 \%$, after recording merely $1 \%$ on the first episode (Yee, 2020). The success of the drama comes as a surprise as the roster of senior actors and actresses is not commercially known among mainstream and international audience that is dominated by the younger generation. However, domestically, they are mostly known for acting credibility and talent due to years of experience and accolades. The success of this drama is not solely achieved through the quality of the acting of the prolific actors and actresses but also the intriguing theme of the drama.

The satirical drama narrates the luxurious life of Korean elites who live in a fictionalized regency called SKY. SKY is an abbreviation for the top universities in Korea; Seoul National University (SNU), Korea University, and Yonsei University, which all are associated with wealth, prestige, and class. Additionally, these three universities are also attended by wealthy ' $0,1 \%$ ' of the Korean population. The series' subject matter is not only about wealth but also extended, if not the primary, to the regency's inhabitants' struggle for social acceptance and to elevate themselves in social hierarchy through education. This drama successfully captures the social condition exposing parental obsession over children's education and its impact.

Four families, namely Kang, Cha, Woo, and Hwang family, are presented in the drama. The first three are willing to do anything to occupy a place in the top universities for their children. In the Kang family, the struggle for education is depicted by the mother (Han Suhjin) and daughter (Kang Yesuh), who fervently show efforts to get into the medical school of SNU. Contrastingly, in the Cha family, the father (Cha Minhyuk) is the only one concerned with his children's education. Initially, his wife (Noh Seunghye) has a similar attitude to that of her husband, but after meeting Lee Sooim from the Hwang family, her perception towards the necessity of education changes.

Among the two families, the responses of children towards the parents' dictatorship appear to be different. In the Kang family, the effort to reach the top is intergenerational. The daughter shows strong aspiration to become socially acknowledged through education that the driving force of her succumbing to her parents' inhumane option under the pretext of embodying their life-long wish of having a child that 
can enroll to Medical School of SNU, a wish shared by the grandparents too. They believe that entering that to SNU ensures social acceptance. In the Cha family, the children are different as they tend to be indifferent towards their study outcomes and supported by the mother. She does not force them to obtain something beyond their capability but has to be subjected to their father's ambition. Under the authoritarian pressure, one term of parenting style typologies is used by Baumrind (in Irawan, 2018) to refer to parents who exercise excessive control over their children's activities. Because of their tyrannical father, they have to study beyond their limit.

Sky Castle is one of the very few Korean dramas that criticizes society's repugnant treatment of education as the determiner of success. Peppered throughout the entire course of the drama are the families' countless inhumane, evil, and immoral attempts to penetrate the wall of competition in the education field. For them, even 'shameful' deeds are morally acceptable if they haul good results concerning the education each of these families envisages. Some instances can be seen, such as hiring a university enrollment coordinator or private tutoring, stealing exam papers, and covering crimes. These extreme instances are carried out to ensure a $100 \%$ acceptance rate for the child. This is ergo correspondent to McVey's (2018) statement that parents in Korea willingly spend more money to afford private tutoring only to improve grades. Hence, ascertaining the opportunity to enroll in a prestigious and good university in the context of Sky Castle can be read as an act of commoditizing education as means to gain cosmopolitan membership.

The two cases of Han Suhjin and Cha Minhyuk show that the tiger parents' consumption of education as a commodity. First, the research will explain the Han Suhjin case. The series starts with Han Suhjin's endeavor to gain information from Lee Myungjoo, who successfully sends her son into the SNU's medical school, unaware of what lies beneath the success. To achieve her goal, she does a series of actions to amuse Lee Myungjoo, such as throwing a fancy party and gluing to her, all of which are mere pretexts to gain portfolio and information about private tutoring. Although her efforts are initially fruitless, her ambition does not immediately dissipate. From when she earns the clue about the private tutor, countless mysteries, criminal acts, and immoral deeds unfold to show how she serves as an epitome of a tiger mother. It also shows how she consumes education by commoditizing it, which gives her the cultural capital to participate in a certain community, where spoon class occupies a significant position as a determiner of someone's social locus.

The process of consuming education aligns with her primary goal of making her daughter successful. Witnessing Lee Myungjoo's disconsolate decision to commit suicide due to severe family ties with her son does not falter her tenacity and resoluteness in intensively meddling with her daughter's education. Her attitude here is a wager in that she is aware of the danger that may come with her decision, but she still manages her daughter's education with an unsavory scheme. Her negligence towards what happens to Lee Myungjoo declares her persistence, which further communicates the idea of will-power (Szutta, 2020). Her humble-beginning stimulates her persistence as she has to camouflage as a rich and educated woman in her married life. Ashamed of her upbringing with a violent father selling ox-blood, her clandestine actions paint her as a rich and educated woman. Additionally, her greed is begotten by pressure from her mother-inlaw, who demands she reproduce a third-generation doctor for the sake of lineage. What her mother-in-law intentionally does can be understood as an attempt to transmit cultural capital to prolong and pass on the social status to the generations that come after her (Bourdieu in Spiegler, 2018). Furthermore, it is also related to the idea of intergenerational social mobility, which, according to many sociologists, is correlated with education (Chung \& Park, 2019).

Her past and mother-in-law's pressure give rise to her obsession with high-class education and agency to perpetuate her current situation. It means that, if not eclipsing it, she is in a quest for betterment after suffering from the harsh 'reality' of her past and mother-in-law's pestering. To elevate her status and image in front of the residents, she strives to make her daughter a successful student. She believes it reflects class and increases the possibility of becoming a doctor, a profession worshipped by the residents. In Addition, it is the dogma that a doctor coming from a prestigious university like SNU is more respectable and secures higher income. Hence, she is willing to spend millions on private tutoring and education for her daughter.

The bodily practice of consumption by Paterson (2006) can best describe her actions. Paterson (2006) has explained that the conceptual body does not solely consume tangible items but also consumes the intangible ones such as education. This bodily consumption is propelled by the complex notion of body, which is lived in or the embodiment experience whereby the body is an integrated aspect of the true inner self (Featherstone as stated in Tyner, 2015). In his work, Paterson (2006) quotes Bourdieu's statement that taste, a class structure turned into nature, that is, embodied, helps to shape the class body, which implies that consumption of commodities, like education, evinces social position and identity. These finds are supported by Slater (1997), who claims everything that has an exchange value can be treated as a commodity, including all social relations, activities, and objects, which can in principle be exchanged as commodities. Ergo, in this sense, education consumption is not solely related to the function of education, but the cultural values imputed to it. With all of the cultural values that education carries, it endows the consumers' ability to become what they want. It means that they construct their identity with the education they aim for. This resonates with Williams' (in Tsang, 2014) idea of the shifting values of education. 
Education serves as the nucleus of the drama, and its exploitation as a commodity for consumption communicates the hegemonic power that education has. It segregates those who have the means to participate in the community and those who do not. Precisely, this notion does not apply in all discourses, but it conforms to certain constructions in the society, and the thriving of education within the Korean peninsula bolsters this particular notion. In the Korean context, middle-class and upper-class families see education as a means of maintaining their current social class. In some other cases, education can be deemed as an exodus. These families try to ensure upward mobility. Hence, what she does for her daughter and herself, is not a mere obsession over education fueled by the sociopolitical situations. It demonstrates her constructed identity and compensates for her humble past. By utilizing her daughter and feeding her' body', she displays herself the way she wants by consuming education which amply possesses assigned cultural values (Slater, 1997). The discourse of Korea's education is informed by ascribed cultural values, such as education substitutes class and education substitutes success.

This is correspondent to the beliefs articulated among the Sky Castle residents, including Han Suhjin. They share similar values that with top-tier education, their children will be able to succeed in society, which in turn elevate their class. Owning this commodity therefore grants her the power to participate in a certain imagined community. It means that by commoditizing education, she communicates more than who she is but also a social membership. It is a bestowment for her to participate in the community of affluent people in Sky Castle. In the context of the series, it is unpenetrable by those who do not possess the means which is promising education and have an elite background. This is evident by the unwelcoming reactions shown by the residents of Sky Castle after they figure out that she has been telling lies about her educational background. Hence, Han Suhjin's class, desire for success, and social membership are closely related to power, which is constructed in the story.

Han Suhjin's steadfastness in securing a seat for her daughter in SNU by exhausting every possible means must not be misconstrued as a paltry wish to enroll in a reputable university. Taking into account the vast array of accolades SNU has, the university proffers prestige to whoever can afford its tuition and successfully enroll in its department amidst tough competition. This prestige is not a single entity, nor is it an adjunct entity; it conjoins itself with power. In this respect, Ergo, through her daughter, exchanges this education with value-laden honor to be seen and respected in the community she participates in.

Furthermore, in a society where education performs as or constitutes the determiner of success, people with lower educational profiles have to toil to survive, and establishing the connection is rather onerous. Materially advantaged families opt for better education based on dispositions that could lead to the maintenance of their position in the social totem pole or engender their upward mobility in society's hierarchical structure. Events dealing with her journey for betterment are informed by the notion, once again, of commodification. This socially and culturally situated commoditizing education process for personal use and pragmatic gains could serve as a site of struggle of ideologies. It implies that the contestation of multiple ideologies is made possible in this process. In Han Suhjin's case, the ideologies of education constituting success and elitism are at play. The former is embodied in how she keeps instilling the idea that her daughter will not be able to succeed as a doctor if she does not become a student at SNU. Only by becoming a doctor at SNU she will become a successful doctor like her predecessors. The ideology of elitism is also at work in how she believes that not being able to enroll into SNU and becoming a doctor like her husband and father-in-law will put her daughter in disdain and does not describe the family lineage and her family's economic background.

To establish an image of an educated woman that fits into the high-class society, she also upskills herself with reading books written by great thinkers such as Plato and Nietzsche, as well as disguising herself as a graduate of a reputable overseas university. Hence, the residents come to the full knowledge that she possesses academic excellence, so it is natural for her daughter to follow the same path. This impersonation is effectuated to render the aforementioned image. Here, she exhibits her 'performing self'. Implied from the term is the idea that she wants to appeal to the residents by exposing her educational background and aspirations for making her daughter the same as her father and mother. Ironically, the residents swallow this impersonation as truth, given her marriage with an acclaimed doctor from a wealthy family. What she publicly endorses becomes her credentials, and the residents do not question it until the truth comes across in a so-called wicked 'symposium' orchestrated under the pretext of discussing the residents' disagreement on Lee Sueim's wish to broadcast the death of Lee Myungjoo, which was caused by education obsession through literary means. Worried that the world outside, Sky Castle might criticize the residents for their irrational obsession with education. She exploits this sentiment to choreograph a situation to humiliate Lee Sueim, whom she detests for not taking an extra mile for her son's education. Unfortunately, cornered by oppositions from the residents, Lee Sueim, who happens to be Han Suhjin's childhood acquaintance, unconsciously reveals Han Suhjin's background as a poor and not quite educated person. Surprised by her husband's indifference and unwillingness to defend her, she recites her origin loudly. Upon hearing this sudden revelation, the residents show polarizing reactions, and Han Suhjin's close friend, Jin Jinhee, starts questioning her for clarification. Starting from this point, Han Suhjin's image as an educated woman seems to have worn out. However, her aspiration to make her daughter succeed academically persists.

Here, a functionalist perspective that heeds the 
pragmatic aspect of education, such as Goldthorpe (2016), can best elaborate the situation. Han Suhjin's situation is informed by his Origin-EducationDestination (OED) model, which consists of social origin, education, and social destination. In this view, education serves as a mediator between her origin as a low-class person and her destination of becoming a person with a desired constructed image within her current milieu. Hence, education that mediates Han Suh-jin's O and D endorses a meritocratic viewpoint, which particularly heeds the importance of self-driven purpose to succeed (Shin, Jahng, \& Kim, 2019).

Han Suhjin is not the only character-focused in the series to portray a mother adopting the tiger parenting style. Cha Minhyuk is also another character worth examining. His intransigence about the kind of education his sons need to undergo and achieve is highlighted in the seventh episode of the series. He replies to his wife, who tries to negotiate with him about his sadistic approach to educating their children. He says that "even if my kids hate me and become revengeful, once they get into SNU, I'm sure they will end up thanking me later in their lives." His reply implies his greed for the intensive education that he requires from his sons, who are academically underperformers. His primary goal is to make sure that his sons' grades would increase because he equates increasing grades with his families' social position. That is why he would resort to explosive exasperation whenever he is informed about his son's failure to achieve the targeted grades. For instance, unable to accept his oldest son's failure in obtaining better grade, while pointing to a miniature of a pyramid, Cha Minhyuk scolds his oldest son, saying,

"Your grandfather who used to wash other people's clothes all his life belonged ... to the very bottom part of this pyramid. But I managed to pass the bar exam with the highest score and became a prosecutor. That's how I climbed the social ladder up to this point (pointing at the middle part of the pyramid). I want to keep climbing the ladder to the very top, but my dream got ruined while helping my father-in-law. And that's why I changed my goal. It doesn't have to be me. My son will have to get to the top. I'll make sure my son gets to the top." (Ep. 4)

The excerpt shows how his desire to provide the best education for his sons and force them to be smart up despite their known academic shortfall is propelled by his personal failure. Failing to achieve the best he thinks he is capable of, he keeps boosting his success academically and offers it as reasoning with his children. He believes that if he can succeed, his children could too. His egotism in being a prosecutor and professor in a university blinds him from comprehensively seeing the sons' academic deficit and their real aspirations as adults. He does not realize that he has made his children subject to scorn and put them in disdain.
Besides, he also holds a sense of competition with Han Suhjin and her daughter, Kang Yesuh, who is academically excellent. Whenever he finds out that Kang Yesuh surpasses his children at school, he would agonize and exercise his authoritarian parenting style towards his sons. He would bring them to a room where he can utilize total control and psychologically infuse them with the idea that 'failure is not acceptable' and 'academic success equals to reaching the top'. These two salient ideas of his actions reside in his failure to become the best himself.

Unlike Han Suhjin who crafts her identity as an educated elite in front of the residents of Sky Castle and goes the whole nine yards with hiring a personal coach who does not only academically train her daughter but also kills Kang Yesuh's competitor (Ep. 15-16) and frames it on another innocent boy, and steals confidential exam papers as the coach has connections with the insiders. It proves Han Suhjin's diffidence in her academic skills that she admits only in front of her daughter. Cha Minhyuk shows different qualities. He believes his academic background as a successful student and professor suffices in helping his sons advance towards acquiring academic mastery. He even says, "I'm sure I can do better than her [at teaching my sons] (referring to an examination coordinator)". His decision can be read as his attempt to be the paragon for his children to gain inspiration. However, he fails to capture the essence of being academically supportive.

Thelearning environmentneeds to becomfortable and supportive in order to create opportunities for better learning. If a learning environment appears to be intimidating and uncomfortable, the chance of bettering academically is low. It gives the sons' attitude and personality that are poles apart from Kang Yesuh, Han Suhjin's daughter. Whenever he teaches his sons in the learning room, what the sons really feel is confinement and suffocation. Hence, what remains from his cruel approach is resentment of his sons, wife, and daughter. In the middle of the series, his sons could hardly consider him a father.

In the fourth episode, Cha Minhyuk is under the suggestion and proposal of his wife, Noh Seughye, to hire an examination coach for his sons. When the coach examines the learning environment in his house and evaluates him by saying,

"You even soundproofed this room (referring to the learning room that is similar to a confinement)... Mr. Cha. This isn't education. You've been rearing them like animals. Haven't you thought that this room could make your sons feel intimidated? Feeling intimidated can significantly dampen brain cell activity. One's ability to reason, understand, and think creatively can be used most effectively in an environment one can feel free. Do you expect your sons to get good grades in this environment?"

Her evaluation of Cha Minhyuk's provision for his sons' education is critical because it highlights 
the degree of his approach's cruelty. However, he refuses to subscribe to her evaluation, and instead, he eschews it. He would then maintain the room and keep intimidating his sons because of his fixation to create smart students who could reach the top of the contemporary Korean social pyramid. However, his urge to have that kind of son is not for his sons' prosperity, but he needs something to flaunt to the residents, something that people can admire him about. His desire to gain respect and admiration from others is also proven through his 'gasconade' about her daughter, who claims to be a Harvard student. However, her daughter has been lying to him and her entire family about going to Harvard because she wants to avoid her father's dictatorship. Not knowing anything about this, he keeps bragging about having a daughter studying at Harvard University. His boasting is even made more possible whenever he meets the residents, mostly from educated and socially higher families. Hence, his obsession over education here is not a mere obsession, but he considers by having children who excel in their studies like him, he has access to the community. He has the means to participate in social practices that are only made possible with education, which also defines his social position and identity.

The cases of Han Suhjin and Cha Minhyuk as exemplary of tiger parents present more than an excessive obsession over education. It carries hedonistic essence if seen from the point of view of consumption. Like previously nuanced, education in these two families can be understood as a commodity consumed for its performativity and pragmatic gains. Contradictory to the Marxist stance on consumption, which is heavily related to production, Paterson (2006) focuses more on the 'cultural forms and symbolic acts'. It is more suitable for analyzing this series that focuses on education as a cultural capital, which is translated into economic capital for its shifted value. As Paterson (2006) highlights in his work, the processes and acts of consumption reveal the complexity of their engagement with 'identity, status, aspirations, cultural capital, and position within a social group'. Both Han Suhjin's and Cha Minhyuk's endeavors to educate and smarten their children, and their selfpresentation and projection as educated individuals are not separated from the identity they intend to project. For them, education is a means to sustain their identity as educated people and the elite. Through education, people perceive this identity projection as it is. The interrelation between education and identity is complex in that both Han Suhjin and Cha Minhyuk project a certain kind of identity through consuming education based on their personal self-reflection. It makes them have to pay as a part of a wealthy family living in an extremely affluent resident and owning a membership to a coterie. Han Suhjin's poverty-stricken background and Cha Minhyuk's failure to reach the top trigger this behavior.

Hence, to assume an identity based on what an individual consumes is not a simple matter to deal with. At times, identity-based on consumptive behavior is not a matter of personal choice that could result in euphoric ambiance or exultation but a matter of choice precipitated by suppression or unfortunate causes. Their situations also highlight what Slater (1997) opines as a dependency of constructed identity on success and social survival. What can infer from Slater's argument is that the consumption of education for both Han Suhjin and Cha Minhyuk primarily denotes their attempt to become engaged with the social environment and obtain success and promising careers, as the education that they pursue their children provides them with cultural capital to reproduce class. Hence, the idea of true identity can be concluded as a fallacy for it is socially constructed. Their educationoriented behavior and consumption also bespeak their social group and their possession of cultural capital. With this possession of Bourdieu's notion of cultural capital, Han Suhjin and Cha Minhyuk are given the capacity to participate in a certain community. In this sense, their social mobility is ascertained. Therefore, it corresponds to Gabay-Egozi \& Yaish's (2019) research, which elaborates how social mobility is primarily linked to education.

In her excellent work on examining the consumption of higher education, despite focusing on the discourse of higher education in the UK and US, Williams' (2012, in Tsang, 2014) elaboration retains resonation with the underlying messages of this series. According to her, the shifting towards the instrumentalization of higher education has diverted the traditional value of education from 'intellectualizing individual' to 'focusing on the instrumental outcomes'. The manifestation of such a phenomenon can be unearthed through the educational policies of universities and the promotion of academic courses as a vehicle to obtain jobs. This neoliberal approach has been institutionalized by many higher education institutions not only in the context of Williams' study but also across the globe, including those in Korea. In that sense, it is safe to say that the unrestrained consumption of education of these two individuals seeking their children for pragmatic gains correspondent to the shifted value of education in the present epoch.

The actions of these two characters analyzed above explicate how the instrumental aspects of education have become the major foci and nucleus of this series. Equipping themselves is no longer for the sake of rudimentary inculcation of knowledge. Instead, it has become a means of achieving a respected career similar to doctor and prosecutor prestige-wise. Therefore, the function of education as a cultural capital has been transformed into economic capital. This transformation ensues due to the idea that the pursuit of top-tier education does not only guarantee cosmopolitan membership but also monetary benefits that come along with such pursuit.

However, the researcher must argue that the series also imparts the integrative aspect of education. For Han Suhjin and Cha Minhyuk, being educated is not merely for the purpose of getting a job that people 
look up to. It is also to integrate themselves into a community that shares similar values. In this circle, they become introjected, and they subscribe to the values shared. That is why Han Suhjin, for example, is willing to forfeit her morality by turning a blind eye on the examination coordinator that she hires and who kills another kid, who discovers the stolen exam paper in Han Suhjin's house, and steals test paper. She is willing to do so because she needs a daughter who can excel academically, a daughter that can help her grasp the sense of belongingness to the Sky Castle, and gain respect from her respected mother-in-law.

\section{CONCLUSIONS}

In Korea, education has been perceived as a definite contributor to an individual's success. The people's zeal for obtaining the best education possible is primarily propelled by an ancient view derived from Confucious. However, in contemporary Korean society, the ardor towards education is rooted in the instrumentality of education. This finds support Joanna Williams's explication that foregrounds the revolutionary social metamorphosis of education. Unlike the traditional view that treats it as a means to gain knowledge, it has shifted towards a broader concept grounded in the sociopolitical slant.

It is interesting that a satirical Korean drama, Sky Castle, documents this phenomenon through the experiences of two parents. Contextualized in Korean society, the salient thematic aspect of this series resonates with the condition of China, and probably other parts of the world that have not been comprehensively explored, where tiger parents would struggle to foster their children with education and when the children do not fulfill the expectations, they are coerced to succeed. Through the depiction of Han Suhjin and Cha Minhyuk, education can be rendered as a site of struggle between ideologies. First, it carries the ideology of education as a constitution of success, and second, it promotes the ideology of elitism. Superficially, these two ideologies can be thought of as a dichotomy, but they bring a similar result that is consumption through commoditizing education. However, contestation of these two ideologies still ensues in the series. It is often on the blurred lines, whether their obsessive behavior towards exploiting education is merely for success or for gaining cosmopolitan membership.

Just like any other commodities, the value of education is an entity that is basically shaped by culture. It offers prestige for the pursuers to mingle with the coterie they aspire to be members of. In Sky Castle, the two characters above also experience mishaps, which lead them to become extra obsessive about education and value it more than other entities. They even disregard the psychological aspects of their children, a profound example of tiger parents, who shatter their morality only to gain access to top-tier education. As a commodity, the value of education is hardly decoded without personal experience. Hence, it is crucial to scrutinize the inseparability of education as a commodity and personal experience. Education's value only becomes apparent when it is experienced, how this experiential aspect is embodied through a personal portfolio or declaration.

It is an exciting inquiry when the extent to which education performs in societal practices is questioned. At times, education as a cultural goods is rarely questioned from the perspective of consumption. However, a more in-depth understanding of its values and functions for some circles of people in the society could shed light on the position of education in the consumer culture.

\section{REFERENCES}

Akua-Sakyiwah, B. (2016). Education as cultural capital and its effect on the transitional issues faced by migrant women in the diaspora. Journal of International Migration and Integration, 17(4), 1125-1142. https:// doi.org/10.1007/s12134-015-0455-8.

Chung, I., \& Park, H. (2019). Educational expansion and trends in intergenerational social mobility among Korean men. Social Science Research, 83, 102307. https://doi.org/10.1016/j.ssresearch.2019.04.020.

Cui, M., Darling, C. A., Coccia, C., Fincham, F. D., \& May, R. W. (2019). Indulgent parenting, helicopter parenting, and well-being of parents, and emerging adults. Journal of Child and Family Studies, 28(3), 860-871. https://doi.org/10.1007/s10826-01801314-3.

Fletcher, K. L., Pierson, E. E., Speirs Neumeister, K. L., \& Finch, W. H. (2020). Overparenting and perfectionistic concerns predict academic entitlement in young adults. Journal of Child and Family Studies, 29(2), 348-357. https://doi.org/10.1007/s10826-01901663-7.

Gabay-Egozi, L., \& Yaish, M. (2019). Intergenerational educational mobility and life course earnings in Israel. Social Science Research, 83, 1-16. https://doi. org/10.1016/j.ssresearch.2019.04.015.

Goldthorpe, J. H. (2016). Social class mobility in modern Britain: Changing structure, constant process. Journal of the British Academy, 4, 89-111. https:// doi.org/10.5871/jba/004.089.

Ha, Y., \& Park, H. J. (2017). Can after-school programs and private tutoring help improve students' achievement? Revisiting the effects in Korean secondary schools. Asia Pacific Education Review, 18(1), 65-79. https:// doi.org/10.1007/s12564-016-9451-8.

Harsono, I. M. (2017). Mediocrity madness: The destructive effects of Antonio Salieri's narcissistic personality disorder in Amadeus. K@Ta, 19(2), 71-76. https:// doi.org/10.9744/kata.19.2.71-76.

Howe, B. (2020). South Korea: Transformative challenges to the economic and political "Miracle on the Han River". Asian Affairs(UK), 47(1), 16-40. https://doi. org/10.1080/00927678.2019.1704469.

Hultberg, P., Calonge, D. S., \& Kim, S. H. (2017). Education 
policy in South Korea: A contemporary model of human capital accumulation? Cogent Economics and Finance, 5(1), 1-16. https://doi.org/10.1080/23 322039.2017 .1389804

Irawan, S. (2018). Tiger mother and her cubs on a stage: 'Tiger' parenting style and its effects in Listen to Me. K@ta, 21(1),33-41. https://doi.org/10.9744/ kata.20.1.33-41.

Kim, H. H. (2019). Parental overprotection and youth suicide behavior in low- and middle-income countries: A multilevel analysis of cross-national data. International Journal of Public Health, 64(2), 173-184. https://doi.org/10.1007/s00038-018-11694.

Kim, J. S., \& Bang, H. (2017). Education fever: Korean parents' aspirations for their children's schooling and future career. Pedagogy, Culture and Society, 25(2), 207-224. https://doi.org/10.1080/14681366.2016.12 52419.

Kim, S. W., Zhang, C., Chung, H., Kim, Y., \& Choi, S. Y. (2020). Why do women value credentials? Perceptions of gender inequality and credentialism in South Korea. International Journal of Educational Development, 73, 102158. https://doi.org/10.1016/j. ijedudev.2020.102158

Kowen, M. R., Jang, M., \& Lee, N. K. (2019). Transforming in awareness of relationship problems due to excessive private education in Korea. International Journal of Qualitative Studies on Health and WellBeing, 14(1), 1-11. https://doi.org/10.1080/1748263 1.2019.1586624.

Kumar, G. (2020). A study on the Korean value system in Korean dramas: Focusing on "Cheese in the Trap". Research Review International Journal of Multidisciplinar, 5(2), 13-21.https://doi.org/10.5281/ zenodo.3801126.

Kwon, K. A., Yoo, G., \& Bingham, G. E. (2016). Helicopter parenting in emerging adulthood: Support or barrier for Korean college students' psychological adjustment? Journal of Child and Family Studies, 25(1), 136-145. https://doi.org/10.1007/s10826-0150195-6.

Kwon, K. A., Yoo, G., \& De Gagne, J. C. (2017). Does culture matter? A qualitative inquiry of helicopter parenting in Korean American college students. Journal of Child and Family Studies, 26(7), 19791990. https://doi.org/10.1007/s10826-017-0694-8.

Levent, F., \& Pehlivan, M. (2017). Confucianism's influence on ethics education in South Korea. Journal of Human Sciences, 14(1), 321-330. https:// doi.org/10.14687/jhs.v14i1.4372.

Li, Y., \& Thorson, E. (2018). Converting cultural capital into economic capital: A hybrid newspaper's content management and performance during economic turbulence. Journal of Media Business Studies, 15(1), 1-23. https://doi.org/10.1080/16522354.2018 .1445159 .

Lin, X. (2019). Purchasing hope: The consumption of children's education in urban China. The Journal of Chinese Sociology, 6(1), 1-26. https://doi. org/10.1186/s40711-019-0099-8.
McVey, M. (2018). Shadow education and the curriculum and culture of schooling in South Korea. International Review of Education, 64(3), 397-401. https://doi. org/10.1007/s11159-017-9675-9.

Oh, I. (2010). Education and development: Why are koreans obsessed with learning? Comparative Sociology, 9(3), 308-327. https://doi. org/10.1163/156913209X12499527665422.

Paterson, M. (2006). Consumption and everyday life. Abingdon: Routledge.

Rössel, J. (2011). Cultural capital and the variety of modes of cultural consumption in the opera audience. The Sociological Quarterly, 52(1), 83-103. https://doi. org/10.1111/j.1533-8525.2010.01192.x.

Segrin, C., Givertz, M., Swaitkowski, P., \& Montgomery, N. (2015). Overparenting is associated with child problems and a critical family environment. Journal of Child and Family Studies, 24(2), 470-479. https:// doi.org/10.1007/s10826-013-9858-3.

Shin, K., Jahng, K. E., \& Kim, D. (2019). Stories of South Korean mothers' education fever for their children's education. Asia Pacific Journal of Education, 39(3), 338-356. https://doi.org/10.1080/02188791.2019.16 07720 .

Slater, D. (1997). Consumer culture and modernity. Cambridge: Polity Press.

Spiegler, T. (2018). Resources and requirements of educational upward mobility. British Journal of Sociology of Education, 39(6), 860-875. https://doi. org/10.1080/01425692.2018.1425131.

Szutta, N. (2020). The virtues of will-power - From a philosophical \& psychological perspective. Ethical Theory and Moral Practice, 23, 325-339. https://doi. org/10.1007/s10677-020-10068-1.

Tan, C. Y., Peng, B., \& Lyu, M. (2019). What types of cultural capital benefit students' academic achievement at different educational stages? Interrogating the meta-analytic evidence. Educational Research Review, 28, 100289. https://doi.org/10.1016/j. edurev.2019.100289.

Tsang, T. L. (2014). Book review of consuming higher education: Why learning can't be bought by Joanna Williams. UCLA Journal of Education and Information Studies, 10(2), 1-4.

Tyner, K. (2015). Body and consumer culture. The Wiley Blackwell Encyclopedia of Consumption and Consumer Studies, 1-3. https://doi. org/10.1002/9781118989463.wbeccs025.

Williams, J. (2012). Consuming higher education: Why learning can't be bought ( $1^{\text {st }}$ Ed.). London: Bloomsbury Academic.

Woo, H., \& Hodges, N. N. (2015). Education fever: Exploring private education consumption motivations among Korean parents of preschool children. Family and Consumer Sciences Research Journal, 44(2), 127142. https://doi.org/10.1111/fcsr.12131.

Yee, Y. (2020). 드라마「sky 캐슬 」에 나타난 아버지와 어머니의 문지기 유형 (Types of parental gatekeeping in drama Sky Castle). The Journal of the Korea Contents Association, 20(1), 593-604. https:// doi.org/10.5392/JKCA.2020.20.01.593. 